\title{
Effect of different carbon sources on proteases secreted by the fungal pathogen Sclerotinia sclerotiorum during Phaseolus vulgaris infection
}

\author{
E.A. Bueno ${ }^{1}$, M.B. Oliveira ${ }^{1}$, R.V. Andrade ${ }^{2}$, M. Lobo Junior ${ }^{3}$ and \\ S. Petrofeza ${ }^{1}$ \\ ${ }^{1}$ Instituto de Ciências Biológicas, Universidade Federal de Goiás, \\ Goiânia, GO, Brasil \\ ${ }^{2}$ Programa de Pós-Graduação em Ciências Genômicas e Biotecnologia, \\ Universidade Católica de Brasília, Brasília, DF, Brasil \\ ${ }^{3}$ Embrapa Arroz e Feijão, Santo Antônio de Goiás, GO, Brasil \\ Corresponding author: S. Petrofeza \\ E-mail: petrofez@uol.com.br
}

Genet. Mol. Res. 11 (3): 2171-2181 (2012)

Received August 3, 2011

Accepted March 2, 2012

Published June 25, 2012

DOI http://dx.doi.org/10.4238/2012.June.25.3

\begin{abstract}
Sclerotinia sclerotiorum (Sclerotiniaceae) is a plant pathogenic fungus that causes white mold disease in vegetable crops, including the common bean (Phaseolus vulgaris). Proteases produced by fungi are normally an important part of the pathogenic process in the host. We examined the effect of different carbon sources - pectin, glucose, and cell wall of $P$. vulgaris on the production of proteases in cultures of $S$. sclerotiorum. These proteases were also assayed in infected $P$. vulgaris plants. Enzyme activity was increased with all carbon sources, but the highest levels were found when pectin was added. Based on realtime quantitative reverse transcription-PCR analyses, protease induction in S. sclerotiorum was found to occur at the level of gene transcription. The finding of increased expression of acid phosphatase 1 and aspartyl
\end{abstract}


protease in vivo in infected $P$. vulgaris plants supports the role of these enzymes in the invasion process of $S$. sclerotiorum.

Key words: Protease; Phaseolus vulgaris; Sclerotinia sclerotiorum; White mold; acp 1; asp5

\section{INTRODUCTION}

The phytopathogenic fungus Sclerotinia sclerotiorum (Lib.) de Bary causes stem rot disease in a vast range of plant species and families, making it one of the most economically important fungal pathogens (Boland and Hall, 1994). S. sclerotiorum uses an infection strategy based on the acidification of the environment via the production of oxalic acid (Magro et al., 1984) and the secretion of numerous cell-wall degrading enzymes. The action of these enzymes, such as endopolygalacturonases, cellulases, pectin lyase, xylanase, $\beta$-galactosidase, and proteases, is believed to facilitate intercellular fungal growth and destabilize host cell integrity (ten Have et al., 2004).

Proteases have been suggested to be involved in many plant-pathogen interactions (Murphy and Walton, 1996; Clark et al., 1997; Farley and Sullivan, 1998; Paris and Lamattina, 1999; Poussereau et al., 2001a). Proteases of various phytopathogenic fungi have been detected in infected host plant tissues, but their precise function has not been elucidated yet. In S. sclerotiorum and Botrytis cinerea the proteolytic activity seems to be correlated with the development of symptoms (Movahedi and Heale, 1990) and the enzymes are considered important virulence factors (Cotton et al., 2002; Rollins, 2003). Proteases are also regarded as antagonists of antifungal proteins secreted as part of the defense responses by the host (Poussereau et al., 2001a; ten Have et al., 2004).

During saprophytic growth and pathogenesis, S. sclerotiorum secretes large amounts of oxalic acid that accumulate in infected tissues and rapidly decrease the ambient $\mathrm{pH}$ (Magro et al., 1984). It has been shown that ambient $\mathrm{pH}$ regulates gene expression (Poussereau et al., 2001a,b; Rollins, 2003; Hegedus and Rimmer, 2005).

We focused our attention on acid proteases in vitro and in planta during the interaction of this phytopathogen with dry bean plants. In this study, we present the characterization of proteases secreted during $S$. sclerotiorum growth in culture medium with different carbon sources and analyze the regulation of both $a c p 1$, a gene that encodes a non-aspartyl acid protease expressed during sunflower cotyledon infection (Poussereau et al., 2001a), and aspS, a gene that encodes an aspartyl protease expressed since the beginning of sunflower cotyledon infection (Poussereau et al., 2001b).

\section{MATERIAL AND METHODS}

\section{Organism and culture conditions}

S. sclerotiorum, strain SPS, was collected from a naturally infected bean plant and grown on Petri dishes containing potato-dextrose-agar (PDA) culture medium for 5 days at $20^{\circ} \mathrm{C}$. Conical flasks containing $20 \mathrm{~mL}$ minimal salt medium $\left(2 \mathrm{~g} \mathrm{NH}_{4} \mathrm{NO}_{3}, 1 \mathrm{~g} \mathrm{KH}_{2} \mathrm{PO}_{4}, 0.1 \mathrm{~g}\right.$ $\mathrm{MgSO}_{4} \cdot 7 \mathrm{H}_{2} \mathrm{O}, 0.5 \mathrm{~g}$ yeast extract, $3 \mathrm{~g}$ DL-malic acid, and $1 \mathrm{~g} \mathrm{NaOH}$ per liter of ddH $\mathrm{H}_{2} \mathrm{O}$ ) were inoculated with a single $3-\mathrm{mm}$ mycelial plug excised from the margin of a 5-day-old $S$. sclero- 
tiorum colony growing on PDA and shaken at $20^{\circ} \mathrm{C}$ for $48 \mathrm{~h}$. The cultures were centrifuged at $2000 \mathrm{rpm}$, washed twice, and used as inoculum in minimal salt medium. The effect of different carbon sources was determined by adding $1 \%$ citrus pectin or $1 \%$ glucose or $1 \%$ cell wall of Phaseolus vulgaris (CWPv). The cultures were grown in conical flasks with constant shaking at $20^{\circ} \mathrm{C}$ for $24-96 \mathrm{~h}$. The $\mathrm{pH}$ of the culture media was recorded daily. The mycelium was harvested by filtration and stored at $-80^{\circ} \mathrm{C}$ until RNA or protein extraction. Culture filtrates were collected, sterilized through a $0.22-\mathrm{mm}$ filter, freeze-dried, and used as the enzyme source.

\section{Bean tissue infection and sampling}

Plants of dry bean cultivar Pérola were grown in 2-kg plastic pots containing soil fertilized with 4-30-16 NPK ( $1 \mathrm{~g} / \mathrm{kg}$ soil $)$ in a greenhouse at $24^{\circ} \pm 2^{\circ} \mathrm{C}$ temperature, $60 \pm 5 \%$ relative humidity under a 16-h light/8-h dark period. Inoculation was performed 10 days after emergence using the toothpick method. Briefly, 1-cm long toothpick ends were poked onto Petri dishes containing PDA culture medium, inoculated with S. sclerotiorum, and grown for 5 days at $20^{\circ} \mathrm{C}$. After this period, toothpick ends wrapped by the pathogen mycelia were introduced into the base of dry bean plant stems $1.0 \mathrm{~cm}$ above the soil surface for inoculation. All plants were kept at $20^{\circ} \mathrm{C}$ and $90 \%$ relative humidity for $48 \mathrm{~h}$ to provide adequate conditions for infection. Tissue samples were collected from the necrotic part of each lesion within $4 \mathrm{~cm}$ of the lesion edges $24,48,72$, and $96 \mathrm{~h}$ post-inoculation (hpi) and immediately frozen in liquid nitrogen prior to RNA and protein extraction.

\section{Protease assays}

This analysis was based on the assay of MacDonald and Odds (1980). The assay mixture contained $0.9 \mathrm{~mL} 1 \%$ BSA in $50 \mathrm{mM}$ sodium citrate buffer, $\mathrm{pH} 3.2$, and $0.2 \mathrm{~mL}$ enzyme solution. After $2 \mathrm{~h}$ at $37^{\circ} \mathrm{C}, 0.4 \mathrm{~mL} 10 \%(\mathrm{w} / \mathrm{v})$ trichloroacetic acid was added. The tubes were stored on ice for $10 \mathrm{~min}$ and then centrifuged (13,000 rpm for $10 \mathrm{~min}$ ). The absorbance of the supernatant was read at $280 \mathrm{~nm}$ and corrected for background using a zero-time control in which trichloroacetic acid was added prior to the enzyme. One unit of enzyme was defined as the amount needed to increase $\mathrm{A}_{280}$ by $0.1 \mathrm{OD}$. Protein determinations were carried out using the method of Bradford (1976). Specific active-site inhibitors were incubated with the enzymes for $30 \mathrm{~min}$ prior to assaying protease activity. The final concentrations for protease inhibitors (Sigma) used were 0.04 M PMSF (serine protease inhibitor), 0.05 M EDTA (metalloprotease inhibitor), $1 \mathrm{M}$ $\beta$-mercaptoethanol (cysteine protease inhibitor), and $0.1 \mathrm{M}$ Pepstatin A (aspartyl protease inhibitor). All protease assays were run in triplicate and data are reported as means \pm SEM.

\section{qRT-PCR}

RNA was extracted from plant and fungal tissue material using the standard protocol of the Trizol reagent (Invitrogen Corp., Carlsbad, CA, USA). RNA was treated with RNAsefree-DNAse I (Invitrogen Corp.), followed by enzyme inactivation (EDTA $2.5 \mathrm{mM}, 65^{\circ} \mathrm{C} / 10$ $\mathrm{min}$ ) and ethanol precipitation to remove any genomic DNA contamination. The sequences of primers used were: acid protease (acpl) (GenBank/EMBL accession No. EU314718) [acp1-F: 5'-GCC ACC CAA AAC GGA GAA T-3' and acp1-R: 5'-GAG GTG AGG ACG GAG TTT TGT T-3']; aspartyl protease (aspS) (GenBank/EMBL accession No. DV643778) [aspS-F: 5'- 
TGC TAC TGG GTC CAA CAT CGT-3' and aspS-R: 5'-TGC GCT TGA TGC ACT TGG T-3'], and the actin gene (act) (GenBank/EMBL accession No. Q11197) [act-F: 5'-CCC CAG CGT TCT ACG TCT-3', act-R: 5'-CAT GTC AAC ACG AGC AAT G-3']. Equal amounts of RNA $(0.5 \mu \mathrm{g})$ were reverse-transcribed using oligo(dT)12-18 primer and submitted to real-time PCR. Amplification assays were carried out with a 7900HT Sequence Detection System ABI PRISM instrument (Applied Biosystems, Carlsbad, CA, USA) in 12- $\mu \mathrm{L}$ reaction mixtures containing $0.4 \mu \mathrm{M}$ of each primer described above, $2 \mathrm{X} 6 \mu \mathrm{L}$ SYBR Green PCR Master mix, and $0.2 \mu \mathrm{L}$ template cDNA. After an initial denaturation step at $95^{\circ} \mathrm{C}$ for $10 \mathrm{~min}$, amplifications were carried out for 40 cycles at $95^{\circ} \mathrm{C}$ for $15 \mathrm{~s}$ and $60^{\circ} \mathrm{C}$ for $1 \mathrm{~min}$. The comparative crossing threshold method, employing the constitutive $S$. sclerotiorum actin gene expression data for normalization, was used to evaluate the fold-change of each gene of interest in the induction sample compared to the control. Each sample was examined in triplicate for all analyzed genes.

\section{RESULTS AND DISCUSSION}

\section{Characterization of protease activity secreted by $S$. sclerotiorum}

\section{The effect of carbon sources on protease activity}

In order to determine the pattern of protease production, S. sclerotiorum grown in a minimal glucose medium was transferred to culture media containing $1 \%$ pectin or $1 \% \mathrm{CWPv}$ or $1 \%$ glucose. Protease activity was detected in cell-free culture filtrates of $S$. sclerotiorum in the presence of all carbon sources tested, but the levels of activity varied depending on the source used (Figure 1A). The activity of these enzymes reached maximum levels $48-72 \mathrm{~h}$ after being transferred to the medium supplemented with pectin or $\mathrm{CWPv}$ and remained stable for several hours (Figure 1A). The highest specific activity was obtained with pectin $(0.69 \mathrm{U} / \mathrm{mg})$ and $\mathrm{CWPV}(0.49 \mathrm{U} / \mathrm{mg})$. No significant levels of protease-specific activity were found in the presence of glucose $(0.065 \mathrm{U} / \mathrm{mg})$. The enzymatic activity was higher in the medium containing pectin, probably due to the release of pectin polymers (oligogalacturonides) in the culture medium resulting from the secretion of hydrolytic enzymes by S. sclerotiorum (Riou et al., 1992).

In culture medium supplemented with $1 \%$ glucose, we observed a reduction in enzyme activity. Hydrolytic enzymes induced when the fungi is subjected to an extra source of carbon undergo a catabolic repression, a behavior commonly found in Aspergillus nidulans. As described by Mathieu and Felenbok (1994) and Panozzo et al. (1998), since this fungus preferentially uses glucose as an energy source, the biosynthesis of enzymes involved in protein degradation is only observed in the absence of easily metabolized carbon, such as glucose. Vautard-Mey and Fevre (2003) showed that when S. sclerotiorum grows in the presence of glucose, it increases the expression of the gene crel and, consequently, this may contribute to the repression of genes that encode enzymes that degrade the host cell wall, such as proteases.

After the transfer, the culture $\mathrm{pH}$ dropped rapidly from 3.5 (12 hpi) to 2.8 (72 hpi) in the medium containing $1 \%$ pectin (Figure 1B). In the culture medium supplemented with $1 \%$ $\mathrm{CWPv}, \mathrm{pH}$ decreased from 4.2 (12 hpi) to 3.9 (48 hpi) and remained constant. Interestingly, the nature of the proteases produced by the pathogen correlates with the acidification of the 
culture medium: when the $\mathrm{pH}$ of the medium fell below $4.0(48-96 \mathrm{~h})$, the acid protease activity noticeably increased (Figure 1A).

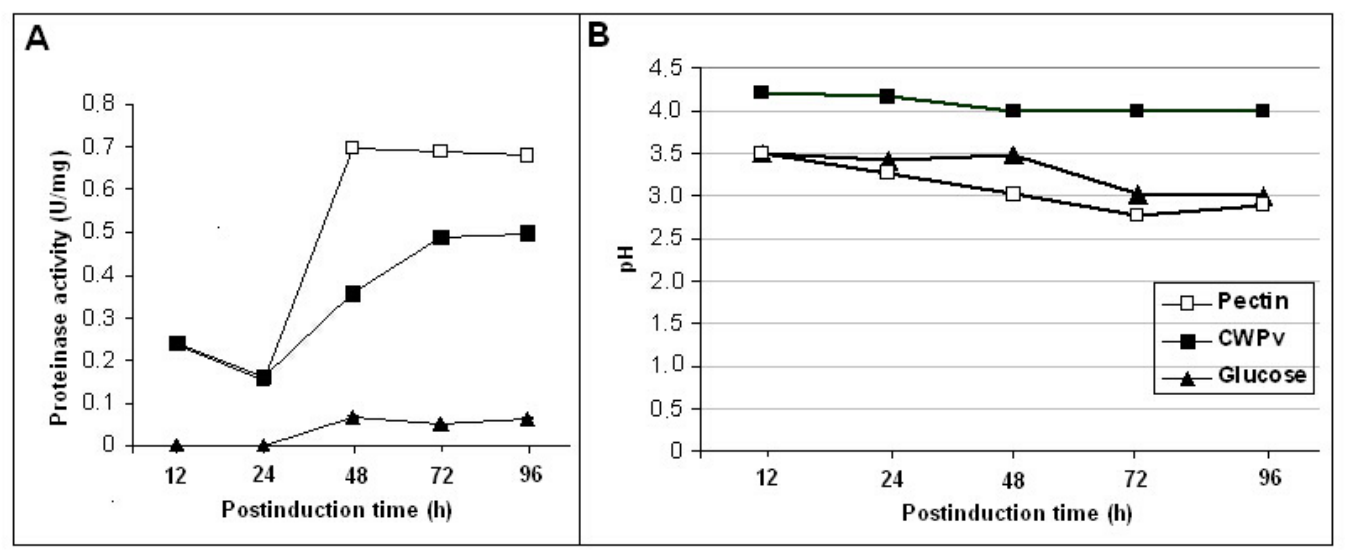

Figure 1. Kinetics of proteolytic activity of Sclerotinia sclerotiorum culture in different carbon sources (pectin, or Phaseolus vulgaris L. cell wall - CWPv, or glucose). A. Proteolytic activity of S. sclerotiorum cultivated in minimal salt media supplemented with $1 \%$ pectin or $1 \% \mathrm{CWPv}$ or $1 \%$ glucose. The enzyme kinetics was performed in citrate buffer at $\mathrm{pH} 3.2$ using BSA as substrate, incubated at $37^{\circ} \mathrm{C}$ (see Material and Methods). Tests on the proteolytic activity were carried out in triplicate. Values are reported as means \pm SEM. B. Comparison of $\mathrm{pH}$ profile evolution in culture media containing different carbon sources.

\section{The effect of $\mathrm{pH}$ and inhibitors on protease activity}

The optimal $\mathrm{pH}$ for protease activity was determined. The highest level of activity was detected at $\mathrm{pH} 3.0$ in cell-free culture filtrates of S. sclerotiorum grown in minimal salt medium, supplemented with either $1 \%$ pectin or $1 \% \mathrm{CWPv}$ extract (Figure $2 \mathrm{~A}$ ). However, enzymes responsible for the protease activity 12-24 hpi seem to belong to different families of proteases, probably acid and neutral and were subjected to temporal influences. No significant differences were observed in protease activity profiles between cell-free culture filtrates of $S$. sclerotiorum grown in minimal salt medium supplemented with pectin or CWPv.

Different protease inhibitors were tested in order to identify the type of protease responsible for this acidic enzyme activity (Figure 2B). PMSF, EDTA, $\beta$-mercaptoethanol, and Pepstatin A, inhibitors of serine, metalloproteases, cysteine and aspartyl proteases, respectively, did not affect this activity completely, indicating that the acidic activity secreted in the medium containing pectin or CWPv extract consists of overlapping activities of different classes of proteases.

Previous studies have shown that aspartyl proteases and acid proteases are secreted by S. sclerotiorum (Poussereau et al., 2001a; Billon-Grand et al., 2002). However, in contrast to what was observed in our study, Billon-Grand et al. (2002) did not observe activity of cysteine protease or metalloprotease secreted by $S$. sclerotiorum in culture medium containing sunflower extracts.

Extracellular proteases are produced by many pathogenic fungi but the profiles of proteases that these organisms produce have often not been fully understood. It has been proposed 
that the range of proteases produced by a fungus reflects the adaptation of saprophytic or pathogenic fungi to the requirements of their ecological niches. In this sense, one can imagine that in response to environmental signals, protease production during pathogenesis must be regulated by the structural cell-wall proteins, nitrogen and/or nutrient limitation, and the ambient pH (Jarai and Buxton, 1994; Poussereau et al., 2001a,b; Billon-Grand et al., 2002; Rolland and Bruel, 2008; Rolland et al., 2009). In S. sclerotiorum for example, secreted proteases with an acidic optimum $\mathrm{pH}$ can be detected when the environment has been acidified via oxalic acid production by this phytopathogenic fungus (Marciano et al., 1983; Magro et al., 1984; Poussereau et al., 2001a; Cotton et al., 2002).

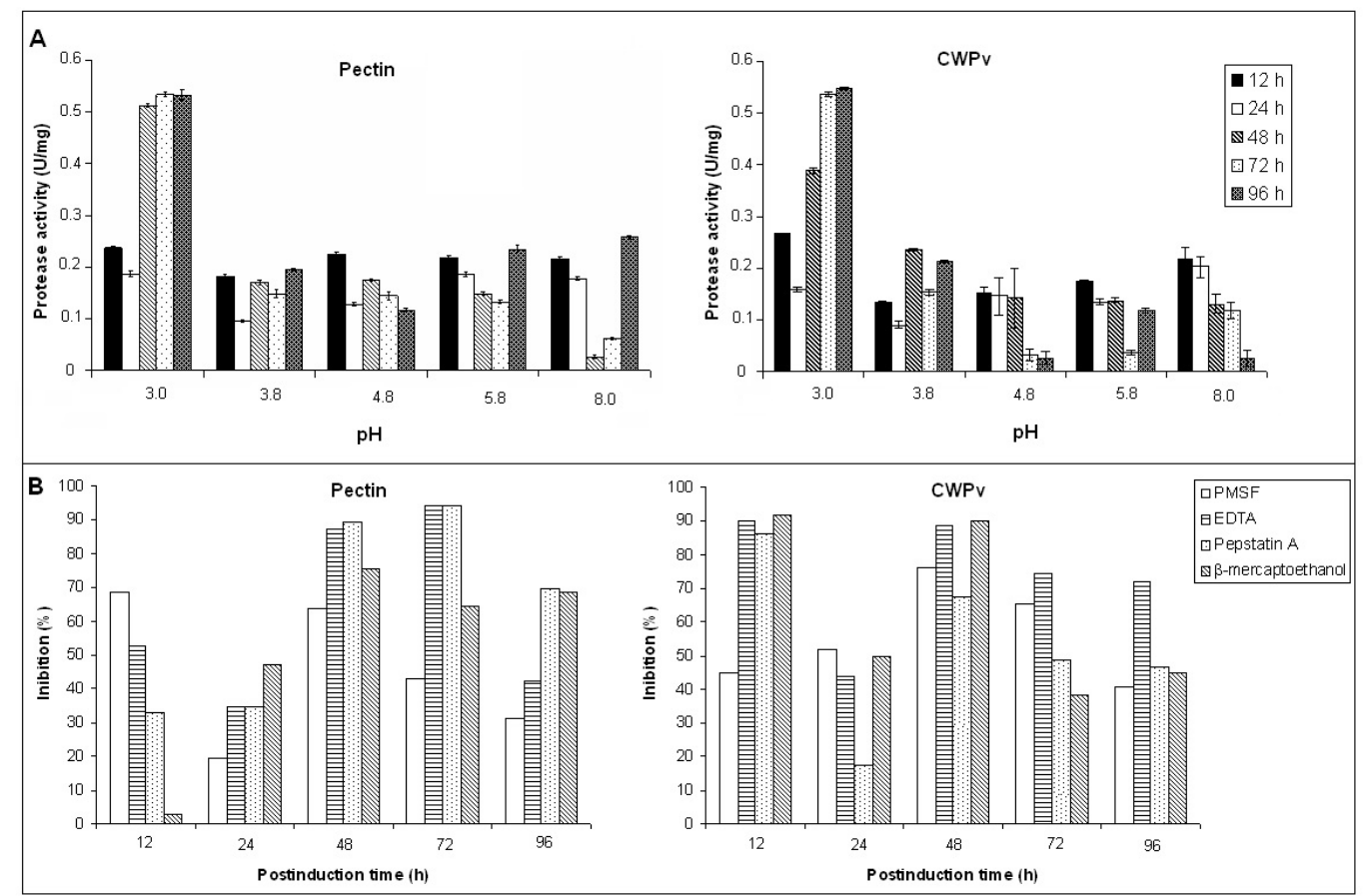

Figure 2. Effect of $\mathrm{pH}$ and inhibitors on the proteinase activity in the culture medium of Sclerotinia sclerotiorum after inoculation with pectin and Phaseolus vulgaris $\mathrm{L}$. cell wall $(\mathrm{CWPv})$. A. Profile of proteolytic activity at different levels of $\mathrm{pH}$. B. Effect of protease inhibitors on proteolytic activity. Classification of inhibitors: PMSF (0.04 M) serine protease inhibitor; EDTA $(0.05 \mathrm{M})$ - metalloproteinase inhibitor; $\beta$-mercaptoethanol $(1 \mathrm{M})$ - cysteine protease inhibitor; Pepstatin A $(0.1 \mathrm{M})$ - aspartyl protease inhibitor. Tests on the proteolytic activity were made in triplicate.

Based on the expressed sequence tag (EST) approach proteases have been identified from $S$. sclerotiorum libraries. cDNAs encoding an acid protease and two aspartic proteases were identified in the infected Brassica napus stem library (Li et al., 2004). Also, cDNAs encoding an aspartyl protease was found only in the infection cushions and a serine protease in libraries prepared from mycelia grown on agar. CaaX prenyl protease, a metalloprotease, was found only in the infected B. napus leaf libraries (Sexton et al., 2006). 


\section{Protease activity during dry bean infection}

Proteolytic activity during the interaction of $S$. sclerotiorum in bean plants was detected $24 \mathrm{~h}$ after inoculation and increased after that. This increased proteolytic activity was correlated with increased intensity of colonization and maceration of host tissue by S. sclerotiorum (Figure 3A and B). However, it is not possible to determine whether the observed activity is derived from the fungus or the plant.

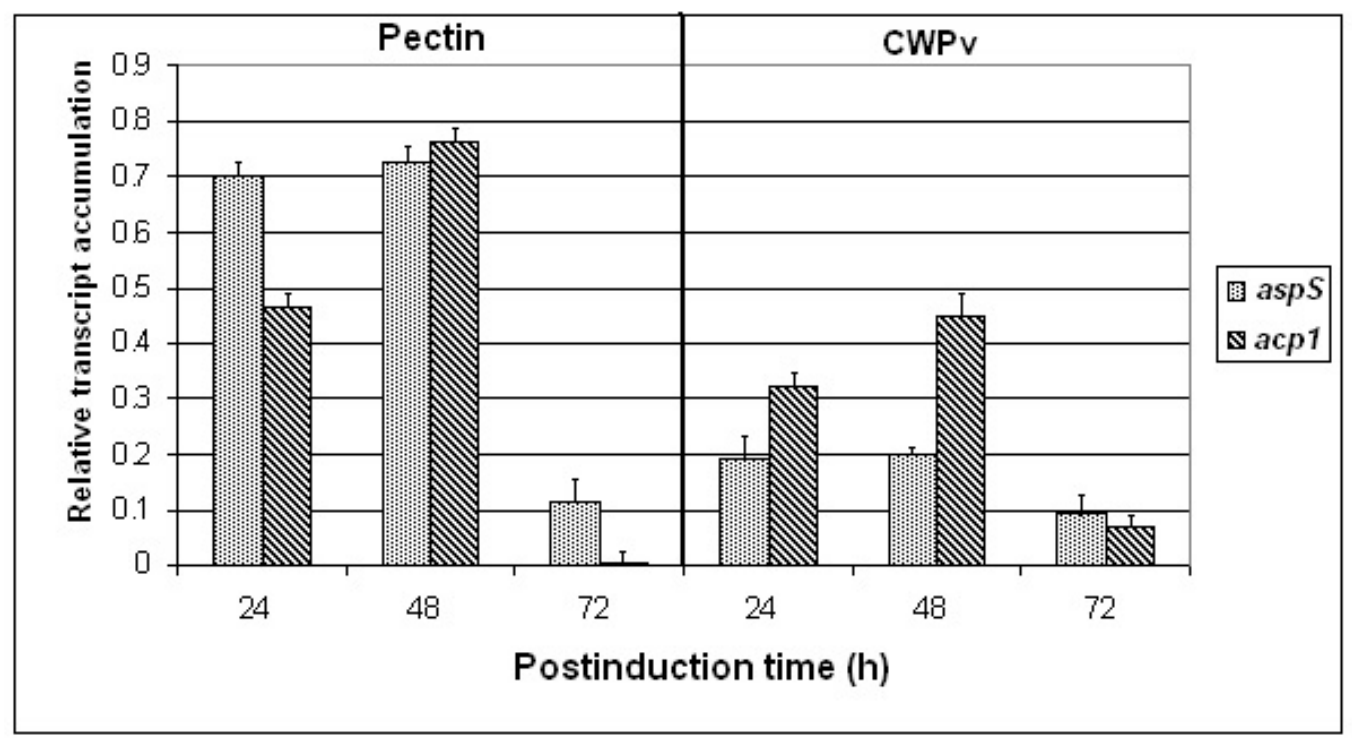

Figure 3. Real-time analysis of transcription patterns of active Sclerotinia sclerotiorum proteinase genes (aspS and acp1) during cultivation of the fungus in culture medium with pectin and Phaseolus vulgaris L. cell wall (CWPv).

\section{Protease expression}

\section{Effects of ambient pH and carbon sources on aspS and acp1 expression}

In order to determine the pattern of aspS and acp 1 expression, $S$. sclerotiorum grown in minimal glucose medium was transferred to culture media containing $1 \% \mathrm{CWPv}$ extracts and 1\% pectin, respectively. Both aspS and acpl genes were expressed during glucose medium pre-culture (data not shown) and also expressed 24-72 $\mathrm{h}$ after transfer to $1 \% \mathrm{CWPv}$ or $1 \%$ pectin media (Figure 3 ). The transcript accumulations were higher in the culture medium containing pectin, indicating that the expression of asp $S$ and acp 1 genes is probably controlled by this carbon source. We presume that these variable differences between the two carbon sources used - CWPv and pectin - occurred because the degradation of pectin polymers may create an environment where low molecular weight products (oligogalacturonides) are released. These compounds serve to induce the expression of a second wave of degradative enzymes that collectively bring about the total dissolution of 
the plant tissue (Hegedus and Rimmer, 2005). In this sense, Pereira et al. (2006) reported that chitin could induce the expression of two different proteases in Aspergillus fumigatus during the process of insect colonization.

During the course of the present $S$. sclerotiorum cultures in unbuffered medium, $\mathrm{pH}$ progressively decreased from 3.5 to 2.8 (as indicated in Figure 1), due to oxalic acid secretion, allowing a strong expression of $a s p S$ and $a c p 1$ during this decrease. And interestingly, aspS and acpl transcript accumulation patterns were down-regulated $72 \mathrm{hpi}$ in both media. As observed in previous studies, the ambient $\mathrm{pH}$ controls the acid protease gene (acpl) expression and may affect aspS expression (Poussereau et al., 2001a,b; Rollins and Dickman, 2001; Rollins, 2003; Kim et al., 2007).

In vitro expression of acp 1 is subject to several transcriptional regulatory mechanisms. Expression induced by plant cell-wall proteins is controlled by both carbon and nitrogen catabolite repression. Ambient $\mathrm{pH}$ higher than 5.0 overrides induction, resulting in full repression of acpl. These transcriptional regulatory mechanisms and the presence of several motifs in the promoter of acpl, which may encode binding sites for the regulators CREA, AREA, and PacC, suggest the involvement of these regulators in the control of acpl expression (Poussereau et al., 2001a; Kim et al., 2007).

Incongruence in the expected transcript accumulation pattern was observed in the aspS expressed gene. Interestingly, our study indicates that aspS expression was modulated during the fungal growth period in culture medium supplemented with CWPv and/or pectin media. In order to determine the effect of carbon and nitrogen sources on aspS expression, Poussereau et al. (2001a) transferred S. sclerotiorum mycelia cultivated in a minimal glucose/ $\mathrm{NH}_{4}$ medium to unbuffered media containing sunflower extracts and glucose, glycerol, and/ or $\mathrm{NH}_{4}$ as carbon and nitrogen sources. Their study showed that in vitro expression of aspS is constitutive and not $\mathrm{pH}$-regulated.

\section{aspS and acp1 expression during dry bean infection}

In order to compare the temporal expression of aspS and acp 1, qRT-PCR experiments were performed on total RNA extracted from $P$. vulgaris stems at different times after inoculation with $S$. sclerotiorum. The transcript putatively corresponding to the aspartyl protease (aspS) increased from the beginning of infection and remained high 72 hpi (Figure 4C). acp1 transcripts, putatively corresponding to an acidic protease, were detected $24 \mathrm{hpi}$ and increased $72 \mathrm{hpi}$. The increase of the transcripts coincided with the phase of symptom development, in which intensive mycelia colonization of the stems occurred (Figure 4A and C). Poussereau et al. (2001a,b) also showed that aspS and acpl were expressed in planta during sunflower cotyledon infection. The authors affirmed that the expression is low at the beginning of infection but increases suddenly at the stage of necrosis spreading.

A dynamic among oxalic acid production, environment $\mathrm{pH}$ acidification, enzyme activity, enzyme gene regulation, and ambient $\mathrm{pH}$-signal transduction has been postulated to play a significant role in Sclerotinia disease development (Rollins, 2003; Hegedus and Rimmer, 2005). In summary, this report provides new information with respect to protease production during S. sclerotiorum host infection. Nevertheless, it is necessary to carry out more studies to further investigate the possible role of proteases in S. sclerotiorum during infection of different hosts. 


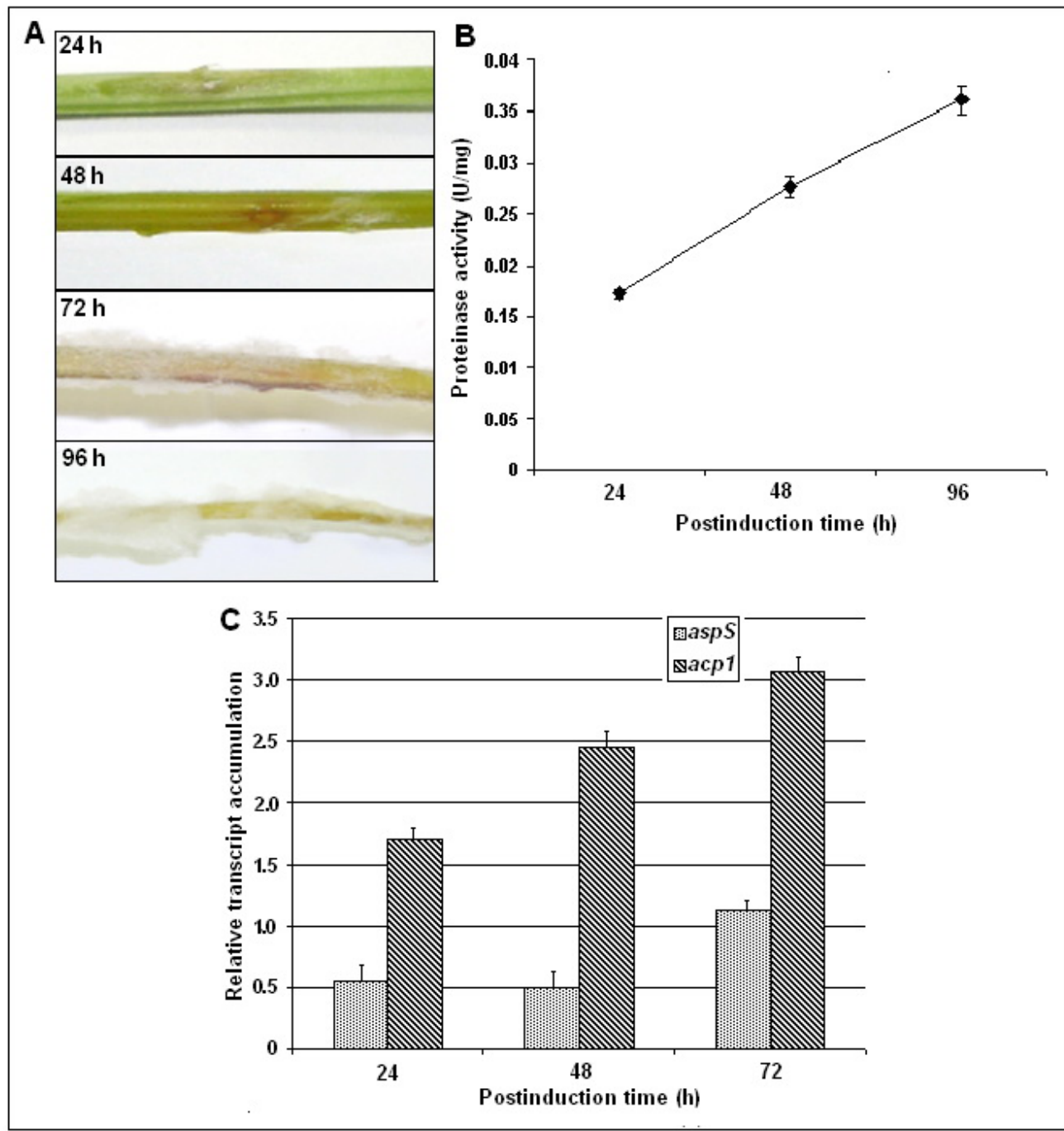

Figure 4. Expression of Sclerotinia sclerotiorum proteinases during pathogenesis. A. S. sclerotiorum-infected bean stem at different times after inoculation. Inoculation performed 10 days after emergence by introducing myceliumcolonized toothpick ends into the base of the stems $1.0 \mathrm{~cm}$ above the soil surface, which were removed to take the photograph in order to show the lesions at the following times: 24, 48, 72, and 96 hpi. B. Kinetics of proteolytic activity of S. sclerotiorum-infected bean stem (see Material and Methods). The enzymatic assay was performed in triplicate and values are reported as means \pm SEM. C. Real-time analysis of transcription patterns of aspS and acp 1 genes of S. sclerotiorum-infected bean stem. Transcript levels estimated using a standard curve for each gene and levels normalized against the amount of fungal actin transcripts in each sample.

\section{ACKNOWLEDGMENTS}

Research supported by Conselho Nacional de Desenvolvimento Científico e Tec- 
nológico (CNPq) and Coordenação de Aperfeiçoamento de Pessoal de Nível Superior (CAPES).

\section{REFERENCES}

Billon-Grand G, Poussereau N and Fevre M (2002). The extracellular proteases secreted in vitro and in planta by the phytopathogenic fungus Sclerotinia sclerotiorum. J. Phytopathol. 150: 507-511.

Boland GJ and Hall R (1994). Index of plant hosts of Sclerotinia sclerotiorum. Can. J. Plant Pathol. 16: 93-108.

Bradford MM (1976). A rapid and sensitive method for the quantitation of microgram quantities of protein utilizing the principle of protein-dye binding. Anal. Biochem. 72: 248-254

Clark SJ, Templeton MD and Sullivan PA (1997). A secreted aspartic proteinase from Glomerella cingulata: purification of the enzyme and molecular cloning of the cDNA. Microbiology 143: 1395-1403.

Cotton P, Rascle C and Fevre M (2002). Characterization of PG2, an early endoPG produced by Sclerotinia sclerotiorum, expressed in yeast. FEMS Microbiol. Lett 213: 239-244.

Farley PC and Sullivan PA (1998). The Rhizopus oryzae secreted aspartic proteinase gene family: an analysis of gene expression. Microbiology 144: 2355-2366.

Hegedus DD and Rimmer SR (2005). Sclerotinia sclerotiorum: when "to be or not to be" a pathogen? FEMS Microbiol. Lett. 251: 177-184.

Jarai $\mathrm{G}$ and Buxton $\mathrm{F}$ (1994). Nitrogen, carbon, and $\mathrm{pH}$ regulation of extracellular acidic proteases of Aspergillus niger. Curr. Genet. 26: 238-244.

Kim YT, Prusky D and Rollins JA (2007). An activating mutation of the Sclerotinia sclerotiorum pac1 gene increases oxalic acid production at low $\mathrm{pH}$ but decreases virulence. Mol. Plant. Pathol. 8: 611-622.

Li R, Rimmer R, Buchwaldt L, Sharpe AG, et al. (2004). Interaction of Sclerotinia sclerotiorum with a resistant Brassica napus cultivar: expressed sequence tag analysis identifies genes associated with fungal pathogenesis. Fungal. Genet. Biol. 41: 735-753.

MacDonald F and Odds FC (1980). Inducible proteinase of Candida albicans in diagnostic serology and in the pathogenesis of systemic candidosis. J. Med. Microbiol. 13: 423-435.

Magro P, Marciano P and Di Lenna P (1984). Oxalic acid production and its role in pathogenesis of Sclerotinia sclerotiorum. FEMS Microbiol. Lett. 24: 9-12.

Marciano P, Di Lenna P and Magro P (1983). Oxalic acid, cell wall degrading enzymes and $\mathrm{pH}$ in pathogenesis and their significance in the virulence of two Sclerotinia sclerotiorum isolates on sunflower. Physiol. Plant Pathol. 22: 339345.

Mathieu M and Felenbok B (1994). The Aspergillus nidulans CREA protein mediates glucose repression of the ethanol regulon at various levels through competition with the ALCR-specific transactivator. EMBO J. 13: 4022-4027.

Movahedi S and Heale JB (1990). Purification and characterization of an aspartic proteinase secreted by Botrytis cinerea Pers ex. Pers in culture and in infected carrots. Physiol. Mol. Plant Pathol. 36: 289-302.

Murphy JM and Walton JD (1996). Three extracellular proteases from Cochliobolus carbonum: cloning and targeted disruption of ALP1. Mol. Plant Microbe Interact. 9: 290-297.

Panozzo C, Cornillot E and Felenbok B (1998). The CreA repressor is the sole DNA-binding protein responsible for carbon catabolite repression of the alcA gene in Aspergillus nidulans via its binding to a couple of specific sites. $J$. Biol. Chem. 273: 6367-6372.

Paris R and Lamattina L (1999). Phytophthora infestans secretes extracellular proteases with necrosis inducing activity on potato. Eur. J. Plant Pathol. 105: 753-760.

Pereira JL, Franco OL and Noronha EF (2006). Production and biochemical characterization of insecticidal enzymes from Aspergillus fumigatus toward Callosobruchus maculatus. Curr. Microbiol. 52: 430-434.

Poussereau N, Creton S, Billon-Grand G, Rascle C, et al. (2001a). Regulation of acpl, encoding a non-aspartyl acid protease expressed during pathogenesis of Sclerotinia sclerotiorum. Microbiology 147: 717-726.

Poussereau N, Gente S, Rascle C, Billon-Grand G, et al. (2001b). aspS encoding an unusual aspartyl protease from Sclerotinia sclerotiorum is expressed during phytopathogenesis. FEMS Microbiol. Lett. 194: 27-32.

Riou C, Freyssinet G and Fevre M (1992). Purification and Characterization of Extracellular Pectinolytic Enzymes Produced by Sclerotinia sclerotiorum. Appl. Environ. Microbiol. 58: 578-583.

Rolland SG and Bruel CA (2008). Sulphur and nitrogen regulation of the protease-encoding ACP1 gene in the fungus Botrytis cinerea: correlation with a phospholipase D activity. Microbiology 154: 1464-1473.

Rolland S, Bruel C, Rascle C, Girard V, et al. (2009). pH controls both transcription and post-translational processing of the protease BcACP1 in the phytopathogenic fungus Botrytis cinerea. Microbiology 155: 2097-2105. 
Rollins JA (2003). The Sclerotinia sclerotiorum pacl gene is required for sclerotial development and virulence. Mol. Plant Microbe Interact. 16: 785-795.

Rollins JA and Dickman MB (2001). pH signaling in Sclerotinia sclerotiorum: identification of a pacC/RIM1 homolog. Appl. Environ. Microbiol. 67: 75-81.

Sexton AC, Cozijnsen AJ, Keniry A, Jewell E, et al. (2006). Comparison of transcription of multiple genes at three developmental stages of the plant pathogen Sclerotinia sclerotiorum. FEMS Microbiol. Lett. 258: 150-160.

ten Have A, Dekkers E, Kay J, Phylip LH, et al. (2004). An aspartic proteinase gene family in the filamentous fungus Botrytis cinerea contains members with novel features. Microbiology 150: 2475-2489.

Vautard-Mey G and Fevre M (2003). Carbon and pH modulate the expression of the fungal glucose repressor encoding genes. Curr. Microbiol. 46: 146-150. 